\title{
Uzunçayır Baraj Gölü’ndeki Capoeta trutta (Heckel, 1843)'nın Üreme Biyolojisi
}

\author{
Fatih GÜNDÜZ ${ }^{1}$ (D), M. Zülfü ÇOBAN ${ }^{2}$ iD , Fahrettin YÜKSEL ${ }^{3}$ (D) Ferhat DEMİROL ${ }^{1}$ (D) \\ Kenan ALPASLAN ${ }^{1}$ iD, Ahmet ALP ${ }^{4}$ iD \\ ${ }^{1}$ Elazığ Su Ürünleri Araştırma Enstitüsü Müdürlüğü, Elazığ \\ ${ }^{2}$ Firat Üniversitesi, Keban Meslek Yüksek Okulu, Keban, Elazığ \\ ${ }^{3}$ Munzur Üniversitesi, Su Ürünleri Fakültesi, Tunceli \\ ${ }^{4}$ Kahramanmaraş Sütçü İmam Üniversitesi, Ziraat Fakültesi, Su Ürünleri Bölümü, Kahramanmaraş \\ $\triangle$ : fatih.gunduz@tarim.gov.tr
}

\section{ÖZET}

Çalışmada, sürdürülebilir avcılık stratejilerinin belirlenebilmesi amacıyla, Uzunçayır Baraj Gölü’ndeki Capoeta trutta'nın üreme özellikleri araştırılmıştır. Balık örnekleri 2013 yılının Ocak-Aralık ayları arasında farklı ağ göz açıklıklarına (36-100 mm) sahip sade uzatma ağlarıyla aylık olarak yakalanmıştır. Araştırma süresince Uzunçayır Baraj Gölü'nden yakalanan 385 adet $C$. trutta bireyinin 218 adedini (\%57.00) erkek, 167 adedini (\%43.00) ise dişi bireylerin oluşturduğu ve populasyonun I-XII yaş grupları arasında dağılım gösterdiği saptanmıştır. GSI değerlerinin mayıs ayında maksimuma ulaştığı, sperm ve yumurtalarını mayıs-temmuz ayları arasında bıraktıkları tespit edilmiştir. Yumurta çapları 0.30-1.07 $\mathrm{mm}$ arasında değişmiştir. Fekondite-total boy ve fekondite-ağırlık arasındaki ilişkileri açıklayan denklemler sırasıyla; $\mathrm{F}=29.708^{*} \mathrm{TL}-$ $593.36(\mathrm{~N}=35, \mathrm{r}=0.27), \mathrm{F}=9.6448^{*} \mathrm{~W}+5488.3(\mathrm{~N}=35, \mathrm{r}=0.38)$ olarak hesaplanmıştır. $C$. trutta bireylerinin yaş gruplarına göre yumurta veriminin 1362-15428 arasında değiştiği belirlenmiştir. Eşeysel olgunluk boyu dişi bireylerde $20.77 \mathrm{~cm}$, erkek bireylerde $19.35 \mathrm{~cm}$ olarak tespit edilmiştir.
DOI:10.18016/ksudobil.296558

\author{
Makale Tarihçesi \\ Received : 06.03.2017 \\ Accepted : 13.04.2017
}

\section{Anahtar Kelimeler \\ Capoeta trutta, \\ Eşeysel Olgunluk Boyu, \\ Uzunçayır Baraj Gölü, \\ Yumurta Çapı}

\section{Araştırma Makalesi}

\section{Reproduction Biology of Capoeta trutta (Heckel, 1843) in the Uzunçayır Dam Lake}

\section{ABSTRACT}

In the study, on the purpose of contribute to sustainable fisheries strategies, the reproductive characteristics of Capoeta trutta in Uzunçayır Dam Lake were investigated. The fish samples were caught from Uzunçayır Dam Lake by using gill nets with different mesh sizes (36-100 mm) between January-December 2013. During research period, a total of $385 C$. trutta samples that were caught from Uzunçayır Dam Lake yielded 167 female (43.00\%) and 218 male $(57.00 \%)$ with an age composition of population varied from I to XII age groups. GSI values reached a maximum in May and rapidly declined after that month, and it can be concluded that $C$. trutta in Uzunçayır Dam Lake deposites its sperms and eggs between May-July. Egg size varied between 0.30-1.07 $\mathrm{mm}$ in dimeter. The relationships between fecundity-total length and fecundity-total weight were determined respectively as; $\mathrm{F}=$ 29.708*TL-593.36 $(\mathrm{N}=35, \mathrm{r}=0.27), \mathrm{F}=9.6448^{*} \mathrm{~W}+5488.3(\mathrm{~N}=35, \mathrm{r}=$ 0.38). The fecundity of $C$. trutta individuals changed from 1362 to 15428 according to age groups. Sexual maturity length was determined as $20.77 \mathrm{~cm}$ and $19.35 \mathrm{~cm}$ for female and males, respectively.

\section{Article History}

Geliş : 06.03.2017

Kabul : 13.04.2017

Keywords
Capoeta trutta,
Egg Diameter,
Sexual Maturity Length,
Uzunçayır Dam Lake

Research Article

To Cited : Gündüz F, Çoban MZ, Yüksel F, Demirkol F, Alpaslan K, Alp A 2018. Uzunçayır Baraj Gölü’ndeki Capoeta trutta (Heckel, 1843)'nın Üreme Biyolojisi. KSÜ Tarim ve Doğa Derg 21(1):51-57, DOI:10.18016/ksudobil.296558. 


\section{GİRIŞ}

Tüm canlılarda olduğu gibi balıklarda da üreme, tür devamlılığını sağlayabilmeleri için yaşamsal öneme sahiptir. Bir balık su kaynağında veya bulunduğu ortamda büyüyüp gelişebilmesine karşın üreme özelliğine sahip değilse o ortama adapte olmuş sayılmamaktadır. Tüm diğer hayvanlar gibi balıklar da genetik olarak üremeye programlanmıştır.

Bir türün üreme başarısı ekolojik koşullara bağlı olarak genetik kapasiteleri tarafindan belirlenmektedir ve bu bağlamda her türün kendine özgü üreme stratejisi vardır. $\mathrm{Bu}$ nedenlerden dolayı başarılı bir balık üretiminin gerçekleşmesi ve balık yetiştiriciliği açısından türlerin üreme biyolojilerinin belirlenmesi önemlidir (Wang ve ark., 2014). Ayrıca, doğal balık stoklarının korunması, sürdürülebilir avcıllğın sağlanması ve balıkçılık yönetim stratejilerinin belirlenmesi için balık populasyonlarının üreme özelliklerinin bilinmesi gerekir.

Uzunçayır Barajı, Tunceli'de, Munzur Nehri üzerinde, enerji üretmek amacıyla 1996-2003 yılları arasında inşa edilmiştir. Kaya gövde dolgu tipi olan barajın gövde hacmi $551 \mathrm{~m}^{3}$, normal su kotunda göl hacmi $308 \mathrm{hm}^{3}$ ve göl alanı $13 \mathrm{~km}^{2}$ dir. Baraj $74 \mathrm{MW}$ güç ile yıllık 317 GWh'lik elektrik enerjisi üretmektedir ve bölgenin önemli HES'lerinden birisidir (URL).

Uzunçayır Baraj Gölü’nde 3 familyaya ait (Salmonidae, Cyprinidae ve Nemacheilidae) 12 takson (Salmo trutta macrostigma (Dumeril, 1858), Acanthobrama marmid Heckel, 1843, Alburnoides bipunctatus (Bloch, 1782), Alburnus mossulensis Heckel, 1843, Barbus lacerta Heckel, 1843, Capoeta trutta (Heckel, 1843), Capoeta umbla (Heckel, 1843), Chondrostoma regium (Heckel, 1843), Cyprinus carpio carpio (Linnaeus, 1758), Squalius cephalus (Linnaeus, 1758), Oxynoemacheilus angorae (Steindachner, 1897), Paracobitis tigris (Heckel, 1843)) yaşamaktadır (Çoban ve ark., 2013).

$\mathrm{Bu}$ taksonlar içinde sadece sazan (Cyprinus carpio carpio) DSİ 9. Bölge Müdürlüğü Keban Su Ürünleri Şube Müdürlüğü tarafından önceki yıllarda aşılanmış olup, diğer taksonların hepsi rezervuarın doğal türüdür.

Capoeta trutta (Heckel, 1843), özellikle Ortadoğu ülkelerinden Türkiye, İran, Irak ve Suriye'de yaygın olarak dağ̊lım gösteren Cyprinidae familyasına ait bir türdür. Bu türün çeşitli su kaynaklarında yaşayan populasyonları hakkında birçok bilimsel araştırma bulunmaktadır (Polat, 1987; Şen ve ark., 1987; Şevik, 1993; Gül ve ark., 1996; Öztürk ve ark., 1997; Yapalak ve Yüksel 1998; Şevik ve ark., 1998; Yılmaz ve Solak 1999; Çalta ve ark., 2001; Örün ve Erdemli 2002; Özekinci ve ark., 2003; Duman, 2004; Çökmez, 2005; Çalta ve Canpolat 2007; Kalkan, 2008; Çoban ve Düşükcan 2009; Mol ve ark., 2010; Yazıcıoğlu ve Yllmaz 2011; Kurt Kaya ve ark., 2013; Gündüz ve ark., 2014).

Uzunçayır Baraj Gölü’ndeki Capoeta trutta’nın üreme biyolojisine yönelik herhangi bir çalışma yapılmamıştır. Bu çalışma ile yeni bir baraj gölü olan Uzunçayır Baraj Gölü’ndeki ekonomik öneme sahip $C$. trutta populasyonunun üreme özelliklerinin araştırılması amaçlanmıştır.

\section{MATERYAL ve METOT}

Çalışma, Ocak-Aralık 2013 tarihleri arasında, Uzunçayır Baraj Gölü (Tunceli)'nde belirlenen 6 istasyonda yürütülmüştür (Şekil 1). Balık örneklemeleri, ağ göz açıklığı 36 ile $100 \mathrm{~mm}$ arasında değişen monofilament sade uzatma ağlarıyla, aylık olarak gerçekleştirilmiştir. Avcılık operasyonlarında toplam 385 adet Capoeta trutta bireyi yakalanmış ve soğuk zinciri kullanılarak incelenmek üzere laboratuvara getirilmiştir.

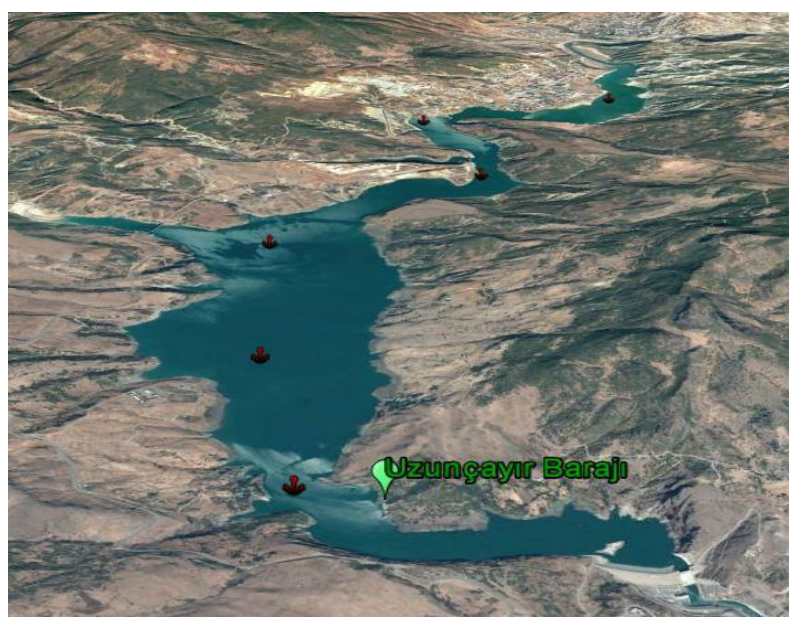

Şekil 1. Uzunçayır Baraj Gölü'ndeki araştırma istasyonlar1

Capoeta trutta örneklerinin total boyu (TB) $1 \mathrm{~mm}$ taksimatlı ölçüm tahtasında, vücut ağırlıkları (VA) ve gonat ağırıkları (GA) ise $0.1 \mathrm{~g}$ hassasiyetindeki dijital terazide belirlenmiştir. Cinsiyet teşhisi, gonatların görsel olarak muayenesi neticesinde gerçekleştirilmiştir. Yaş tahminleri dorsal yüzgeç ışını kullanılarak yapılmıştır (Polat 1986; Öztürk ve ark., 1997).

Üreme döneminin tespit edilmesi amacıyla aşağıdaki formüller kullanılarak aylık periyotlarda gonadosomatik indeks değerleri (GSI) ve kondisyon faktörleri (KF) hesaplanmıştır (Avşar, 1998).

$$
\begin{aligned}
& \mathrm{GSI}=[\mathrm{GA} /(\mathrm{VA}-\mathrm{GA})] * 100 \\
& \mathrm{KF}=\left[(\mathrm{VA}-\mathrm{GA}) / \mathrm{TB}^{3}\right] * 100
\end{aligned}
$$

Yumurta çapları oküler mikrometre ile [(uzun eksen uzunluğu+kısa eksen uzunluğu)/2] formülü kullanılarak ölçülmüştür (Çelik ve Bircan, 2004).

Fekondite, yumurtlama evresindeki dişi bireyler kullanılarak tahmin edilmiştir. Mutlak fekondite (MF) ve Nispi fekonditeyi (NF) belirlemek için gravimetrik yöntem kullanılmıştır (Bagenal ve Braum, 1978). Her bir ovaryumun başından, ortasından ve sonundan $1 \mathrm{~g}$ yumurta alınarak karıştırılmış ve \%10'luk formaldehit çözeltisinde bekletilmiştir. Daha sonra yumurtalar sayılmıştır. Mutlak fekondite, 1 g'daki ortalama yumurta sayısı ile ovaryum ağırlığının çarpılması, nispi fekondite ise mutlak fekonditesinin vücut ağırlığına bölünmesi ile her bir birey için hesaplanmıştır (Wang ve ark., 2014). 
İlk eşeysel olgunluk boyu ile ilgili veriler denkleminden yararlanılarak belirlenmiş ve lojistik eğriler çizilmiştir (King, 1995; Yalçın ve ark. 2004; Alp ve ark., 2005; Ceyhun ve Erdoğan 2008).

$$
\mathrm{P}=1 /\left(1+\exp ^{[\mathrm{r}(\mathrm{L}-\mathrm{Lm})])}\right.
$$

Formüldeki;

P: Her boy grubundaki olgun bireylerin oranını,

L: Total boyu,

$\mathrm{L}_{\mathrm{m}}=$ İlk eşeysel olgunluk boyunu,

r: Elde edilen lojistik eğrinin eğimini ifade etmektedir.

Fekondite-vücut ağırlı̆̆ (F-VA), Fekondite-total boy (FTB), Fekondite-yumurta çapı (F-YÇ) ve Fekondite-yaş grubu (F-t) arasındaki ilişkilerin belirlenmesinde regresyon analizi kullanılmıştır (Bingel, 2002). Elde edilen verilerin istatistiksel analizi için Microsoft Office Excel 2010 ve SPSS 22.0 paket programlarından yararlanılmıştır. Elde edilen istatistiksel bulgular Fowler ve Cohen (1992)'e göre yorumlanmıştır.

\section{BULGULAR}

\section{Cinsiyet ve Eşey Oranı}

Araştırma süresince Uzunçayır Baraj Gölü’nden toplam 385 adet $C$. trutta bireyi yakalanmıştır. Bu bireylerin 218 adedini (\%57.00) erkek, 167 adedini (\%43.00) dişi bireylerin oluşturduğu ve erkek:dişi oranının 1:0.77 olduğu tespit edilmiştir. Bu oranın, beklenen cinsiyet oranından (1:1) istatistiki olarak farklı olmadığı görülmüştür $\left(\mathrm{X}^{2}=3.38 ; \mathrm{p}>0.05\right)$.

\section{Kondisyon Faktörü}

Ortalama kondisyon faktörü, hem dişi hem de erkeklerde Nisan ayında en yüksek seviyeye ulaşmış (Dişilerde: 1.16; Erkeklerde: 1.10), sonraki aylarda düşüş gerçekleşmiştir. En düşük seviyeye ulaştığı (Dişilerde: 0.88; Erkeklerde: 0.82) Temmuz ayından sonra tekrar yükselmeye başlamıştır (Şekil 2). Kondisyon faktörü değerlerinin aylara göre değişimi her iki eşey için de istatistikî olarak önemli bulunmuştur (Anova testi; dişilerde $\mathrm{F}=6.687 \mathrm{p}<0.05$ ve erkeklerde $\mathrm{F}=14.110$ $\mathrm{p}<0.05)$.

\section{Gonadosomatik Indeks}

C. trutta populasyonunun üreme zamanını saptamak amaciyla her eşeyin aylara göre gonadosomatik indeks (GSI) değerleri hesaplanmıştır. Her iki eşeyde de ortalama GSI değerlerinin Mayıs ayında maksimuma ulaştığı (Dişilerde: 4.187; Erkeklerde: 2.830) ve daha sonra hızla düştüğü belirlenmiştir (Şekil 3). Kondisyon faktörü ve gonadosomatik indeks değerleri incelendiğinde üremenin Mayıs ayında başladığı ve Temmuz ayında sona erdiği saptanmıştır. GSI değerlerinin aylara göre değişimi her iki eşey için de istatistikî olarak önemli bulunmuştur (Anova testi; dişilerde $\mathrm{F}=2.197 \mathrm{p}<0.05$ ve erkeklerde $\mathrm{F}=10.231 \mathrm{p}<0.05$ )

\section{Yumurta Çapı}

C. trutta populasyonuna ait dişi bireylerin yumurta çapları aylık periyotlarda ölçülmüştür. En küçük ortalama yumurta çapı Kasım ayında $(0.30 \mathrm{~mm})$, en yüksek ortalama yumurta çapı değeri ise üreme döneminin başladığı Mayıs ayında (1.07 $\mathrm{mm})$ saptanmıştır (Şekil 4). Yumurta çapı yaş grubu arttıkça küçülmüş, ortalama $0.58 \pm 0.06 \mathrm{~mm}$ olarak bulunmuştur (Çizelge 1).

Çalışma süresince ovaryum içinde farklı büyüklük ve renkte yumurtalar tespit edilmiştir. Olgunlaşmamış yumurtaların yeşilimsi-gri ile kirli beyaz renkte, olgun yumurtaların ise portakal sarısı renginde olduğu görülmüşsür.

\section{Fekondite}

Uzunçayır Baraj Gölü $C$. trutta populasyonundan yakalanan yumurtlama evresindeki 36 bireyde fekondite araştırılmıştır. Mutlak fekonditenin yaşa bağlı olarak arttığı ve ortalamasının $6546 \pm 637$ adet olduğu belirlenmiştir. Nispi fekondite, tüm yaş gruplarının ortalaması alındığında, $232.7 \pm 21.3 \mathrm{adet} / \mathrm{cm}$ ve $29.7 \pm 2.6$ adet/g olarak hesaplanmıştır (Çizelge 1).

Uzunçayır Baraj Gölü'nde yaşayan $C$. trutta'nın fekondite-vücut ağırlığı, fekondite-total boy ve fekonditeyaş grubu arasındaki ilişkiyi açıklayan denklemler hesaplanmıştır. Fekondite-vücut ağırlığı ile fekonditetotal boy arasında zayıf düzeyde $(\mathrm{r}=0.38 ; \mathrm{r}=0.27)$ bir ilişki olduğu bulunmuştur.

Fekondite-yaş grubu arasında ise pozitif yönde kuvvetli bir ilişki olduğu (r=0.91) tespit edilmiştir (Şekil 5, 6, 7).

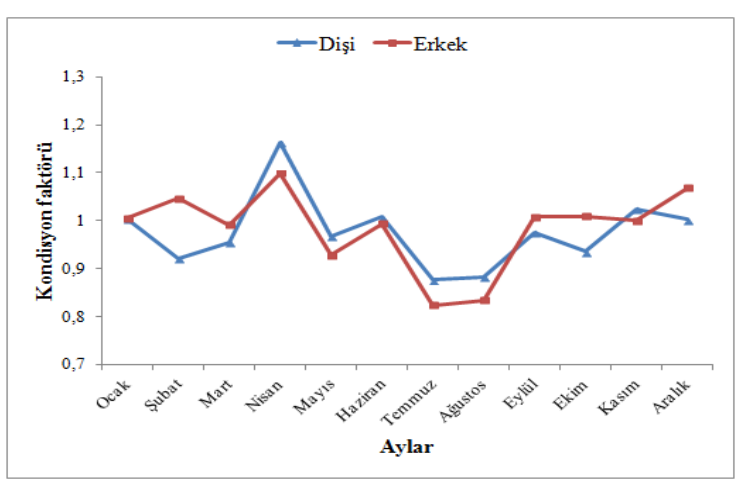

Şekil 2. Kondisyon faktörü değerlerinin eşeylere ve aylara göre değişimi

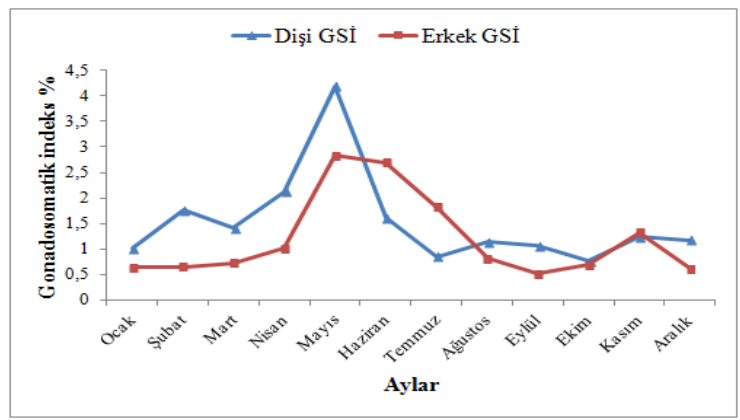

Şekil 3. Gonadosomatik indeks (GSI) değerlerinin eşeylere ve aylara göre değişimi 


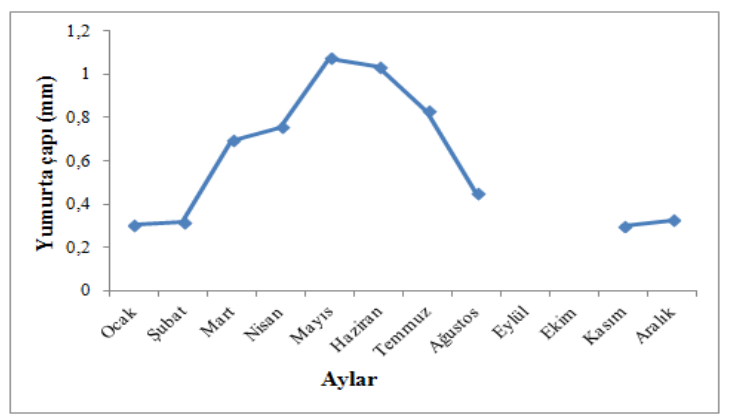

Şekil 4. Yumurta çapı değerlerinin aylara göre değişimi

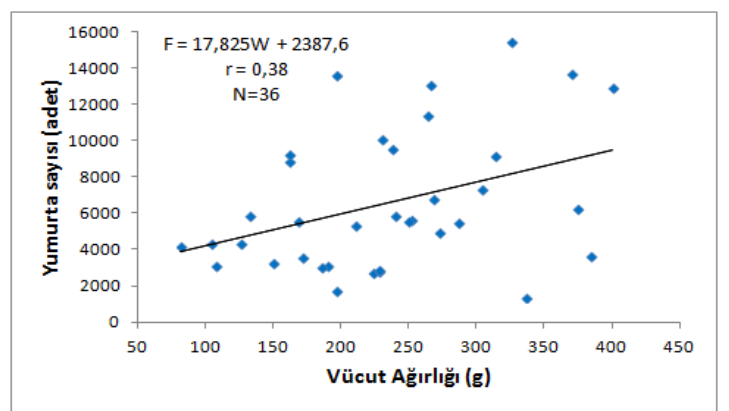

Şekil 5. C. trutta populasyonunun fekondite-vücut ağırlığ

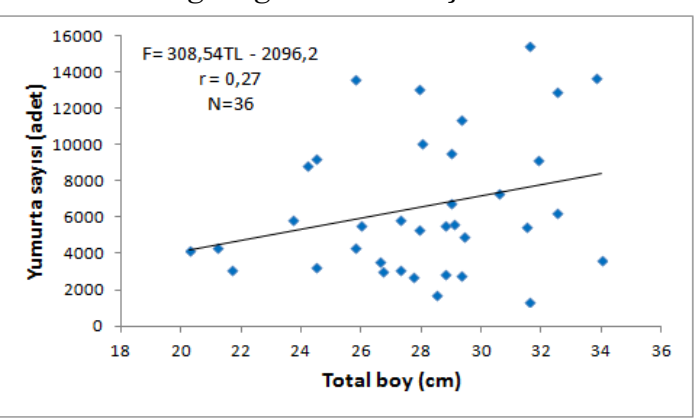

Şekil 6. C. trutta populasyonunun fekondite-total boy (F-TB) ilişkisi

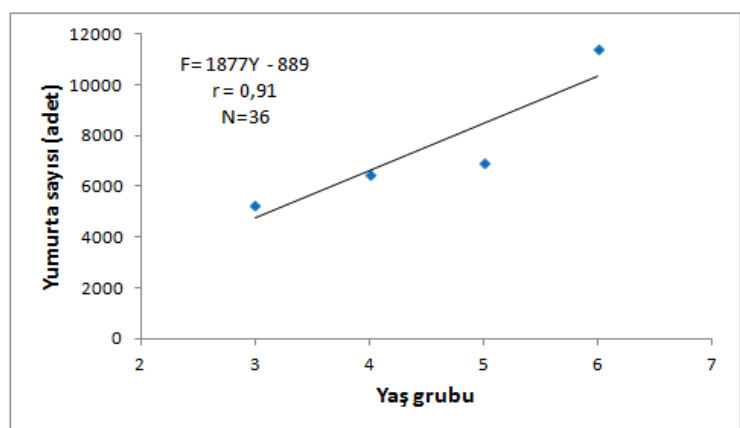

Şekil 7. C. trutta populasyonunun fekondite-yaş grubu (F-t) ilişkisi

\section{Eşeysel Olgunluğa Ulaşma Boyu}

C. trutta bireylerinin \%50'sinin cinsi olgunluğa ulaştığı boyun (Lm= \%50) erkek ve dişiler için sırasiyla; $19.36 \mathrm{~cm}$ ve $20.78 \mathrm{~cm}$ olduğu, erkeklerin boyca daha erken cinsi olgunluğa ulaştığı saptanmıştır (Şekil 8).

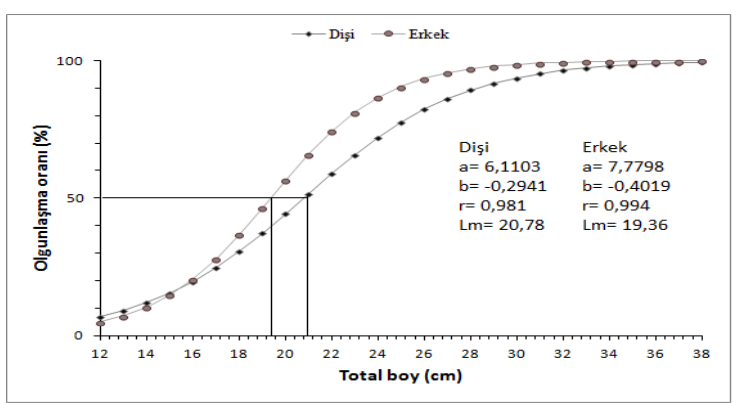

Şekil 8. C. trutta populasyonunun erkek ve dişi bireylerinde ilk eşeysel olgunluğa ulaşma boyu

Çizelge 1. Yaş gruplarına göre total boy (TB), vücut ağırlığı (VA), yumurta çapı (YÇ), mutlak fekondite (F) ve nisbi fekondite $(\mathrm{F} / \mathrm{cm}, \mathrm{F} / \mathrm{g})$ değerleri

\begin{tabular}{llllllll}
\hline Yaş & N & TB $(\mathrm{cm})$ & VA $(\mathrm{g})$ & YÇ $(\mathrm{mm})$ & $\mathrm{F}$ & $\mathrm{F} / \mathrm{cm}$ & F/g \\
\hline III & 7 & $27.4 \pm 1.3$ & $215.7 \pm 30.4$ & $0.80 \pm 0.18$ & $5320 \pm 1468$ & $185.3 \pm 39.8$ & $23.5 \pm 3.1$ \\
IV & 18 & $27.8 \pm 0.9$ & $234.8 \pm 21.4$ & $0.58 \pm 0.08$ & $6521 \pm 908$ & $238.3 \pm 32.8$ & $31.2 \pm 4.4$ \\
V & 10 & $28.8 \pm 0.9$ & $239.8 \pm 24.9$ & $0.46 \pm 0.07$ & $6960 \pm 1210$ & $240.0 \pm 38.5$ & $30.0 \pm 4.3$ \\
VI & 1 & $29.3 \pm 0.0$ & $264.0 \pm 00.0$ & $0.41 \pm 0.00$ & $11430 \pm 000$ & $390.1 \pm 00.0$ & $43.3 \pm 0.0$ \\
\hline Toplam & 36 & $28.0 \pm 0.6$ & $233.3 \pm 13.7$ & $0.58 \pm 0.06$ & $6546 \pm 637$ & $232.7 \pm 21.3$ & $29.7 \pm 2.6$ \\
\hline
\end{tabular}

\section{TARTIŞMA ve SONUÇ}

Çalışma süresince incelenen 385 adet Capoeta trutta bireyinin çoğunluğunu erkekler oluşturmasina rağmen (erkek:281 adet; dişi 167), belirlenen erkek/dişi oranının (1:0.77), beklenenden (1:1) istatistiki olarak farklı olmadığı tespit edilmiştir.

Kondisyon faktörü değerlerine bakıldığında, Nisan ayında en yüksek seviyeye ulaştığı, daha sonra hızla düştüğü görülmüştür.

GSI değerlerindeki aylık değişimler analiz edilmiş ve üreme döneminin Mayıs ayında başladığı ve Temmuz ayında sonlandığı tespit edilmiştir. $\mathrm{Bu}$ dönemde kondisyon faktörü değerlerinin de üremeye bağlı olarak düştüğü belirlenmiştir.

Aynı türün üreme dönemini; Polat (1987), Aşağı Fırat Suyunda Haziran ayında; Çökmez (2005), Karakaya Baraj Gölünde ve Oymak ve ark. (2008), Atatürk Baraj Gölü’nde mayıs-haziran ayları arasında; Düşükcan ve Çalta (2012), Keban, Karakaya ve Atatürk Baraj Göllerinde sırasıyla mayıs-haziran, haziran-temmuz ve haziran-ağustos ayları arasında bildirmişlerdir. 
Elde ettiğimiz değerler diğer çalışmalarla karşılaştırıldığında genelde bir uyum görülmektedir. Farklı su ortamlarında özellikle sıcaklık farklılıklarından dolayı aynı türün üreme döneminin farklı olması beklenen bir durumdur.

En yüksek ortalama yumurta çapı değeri üreme döneminin başladığı Mayıs ayında (1.07 mm) saptanmıştır. Yumurta çapı yaş grubu arttıkça küçülmüş, ortalama $0.58 \pm 0.06 \mathrm{~mm}$ olarak bulunmuştur.

Bazı araştırmacılar Polat (1987), Örün ve Erdemli (2002), Çökmez (2005), Bozkurt (1998), Oymak ve ark. (2008), Düşükcan ve Çalta (2012), Yüce ve ark. (2014), farklı su kaynaklarındaki Capoeta trutta için yumurta çapını 0.09 ile $2.20 \mathrm{~mm}$ arasında bildirmişlerdir (Çizelge 2). Aynı türe ait farklı populasyonlarda yumurta çapları farklı olabileceği gibi aynı zamanda, mevsime, yaşa ve ovaryum içerisindeki konumuna göre de değişebilmektedir.

Fekonditenin yaşa bağlı olarak arttığı ve yaş

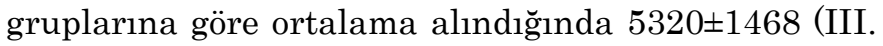

yaş grubu) ile $11430 \pm 000$ (VI. yaş grubu) arasında değiştiği belirlenmiştir. Bu konuda farklı araştırmalar tarafından faklı sonuçlar elde edilmiştir. Yumurta verimini; Polat (1987), 1259-20935; Örün ve Erdemli (2002), 10440-61425; Oymak ve ark. (2008), 687133252; Düşükcan ve Çalta (2012), Keban Baraj Gölünde, 2870-29930; Karakaya Baraj Gölünde, 519256000 ve Atatürk Baraj Gölü'nde ise 3381-45125 olarak bildirmişlerdir.

İlk eşeysel olgunluk boyu erkekler için $19.36 \mathrm{~cm}$ ve dişiler için $20.78 \mathrm{~cm}$ olarak belirlenmiştir. Farklı bölgelerde yapılan araştırmalarda bu değerler erkekler için 19.90-22.95 cm arasında, dişiler için 19.90-25.44 cm arasında bildirilmiştir. Çalışmalardaki bulgular ile bizim çalışmamızdaki bulgular arasında büyük oranda uyum görülmektedir. Eşeysel olgunluğa ulaşma boyu, türe ve türün yaşadığı su ortamının fiziksel kimyasal ve biyolojik özelliklerine göre bazı farklılıklar gösterebilmektedir.

Çizelge 2. Farklı çalışmalardan elde edilen Capoeta trutta 'ya ait üreme biyolojisi ile ilgili parametreler

\begin{tabular}{|c|c|c|c|c|c|c|c|c|c|}
\hline \multirow{2}{*}{ Kaynak } & \multicolumn{2}{|l|}{ GSİ } & \multicolumn{2}{|c|}{$\begin{array}{l}\text { Eşeysel } \\
\text { Olgunluk Boyu }\end{array}$} & \multirow[t]{2}{*}{$\begin{array}{l}\text { Üreme } \\
\text { Dönemi }\end{array}$} & \multirow[t]{2}{*}{$\begin{array}{l}\text { Yumurta } \\
\text { Çapı }\end{array}$} & \multirow[t]{2}{*}{$\begin{array}{l}\text { Yumurta } \\
\text { Verimi }\end{array}$} & \multicolumn{2}{|c|}{$\begin{array}{l}\text { Kondisyon } \\
\text { Faktörü }\end{array}$} \\
\hline & $\pi$ & 우 & 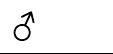 & ㅇ & & & & $\sigma^{\pi}$ & 우 \\
\hline 1 & & $\begin{array}{l}0.92^{-} \\
4.37\end{array}$ & & & Haz. & & $\begin{array}{l}1259^{-} \\
20935\end{array}$ & $\begin{array}{r}1.3 \\
(\mathrm{~d}\end{array}$ & \\
\hline 2 & & $\begin{array}{l}0.67^{-} \\
9.75^{-}\end{array}$ & $20.23^{*}$ & $19.93^{*}$ & May.-Ağ. & $0.41-1.76$ & & $\begin{array}{l}1.12^{-} \\
1.36\end{array}$ & $\begin{array}{l}1.12^{-} \\
1.36\end{array}$ \\
\hline 3 & & $\begin{array}{l}0.82^{-} \\
10.2\end{array}$ & & & $\begin{array}{l}\text { Haz.- } \\
\text { Tem. }\end{array}$ & $0.68-1.11$ & $\begin{array}{l}10440^{-} \\
61425\end{array}$ & & \\
\hline 4 & & $\begin{array}{l}0.29^{-} \\
7.91\end{array}$ & & & $\begin{array}{l}\text { Mart- } \\
\text { Haz. }\end{array}$ & $0.37-1.04$ & & $\begin{array}{l}1.22^{-} \\
1.38\end{array}$ & $\begin{array}{l}1.15^{-} \\
1.33\end{array}$ \\
\hline 5 & $\begin{array}{l}0.76^{-} \\
5.53\end{array}$ & $\begin{array}{l}0.88^{-} \\
8.65\end{array}$ & $19.90^{*}$ & $19.90^{*}$ & $\begin{array}{l}\text { May.- } \\
\text { Haz. }\end{array}$ & $0.42-1.69$ & $\begin{array}{l}6871^{-} \\
33252\end{array}$ & & \\
\hline $6 a$ & $\begin{array}{l}0.39^{-} \\
1.32\end{array}$ & $\begin{array}{l}0.42^{-} \\
2.61\end{array}$ & & & $\begin{array}{l}\text { May.- } \\
\text { Haz. }\end{array}$ & $0.60-1.10$ & $\begin{array}{l}2870^{-} \\
29930\end{array}$ & $\begin{array}{l}1.16^{-} \\
1.51\end{array}$ & $\begin{array}{l}1.05^{-} \\
1.41\end{array}$ \\
\hline $6 b$ & $\begin{array}{l}0.60^{-} \\
2.38\end{array}$ & $\begin{array}{l}0.66^{-} \\
2.85\end{array}$ & & & $\begin{array}{l}\text { Haz.- } \\
\text { Tem. }\end{array}$ & $0.60-1.20$ & $\begin{array}{l}5192^{-} \\
56000\end{array}$ & $\begin{array}{l}1.08^{-} \\
1.45\end{array}$ & $\begin{array}{l}1.16^{-} \\
1.38\end{array}$ \\
\hline $6 c$ & $\begin{array}{l}0.57^{-} \\
4.07\end{array}$ & $\begin{array}{l}0.91^{-} \\
7.95\end{array}$ & & & Haz.-Ăg. & $0.50-2.20$ & $\begin{array}{l}3381^{-} \\
45125\end{array}$ & $\begin{array}{l}1.18^{-} \\
1.51\end{array}$ & $\begin{array}{l}1.17^{-} \\
1.52\end{array}$ \\
\hline $7 \mathrm{a}$ & $\begin{array}{l}0.49^{-} \\
7.76\end{array}$ & $\begin{array}{l}0.72^{-} \\
5.91\end{array}$ & 22.55 & 24.06 & May.-Ağ. & $0.76-1.59$ & $\begin{array}{l}1809- \\
45313\end{array}$ & $\begin{array}{l}1.13^{-} \\
1.27\end{array}$ & $\begin{array}{l}1.10^{-} \\
1.36\end{array}$ \\
\hline $7 \mathrm{~b}$ & $\begin{array}{l}0.53^{-} \\
12.8\end{array}$ & $\begin{array}{l}0.55^{-} \\
10.0\end{array}$ & 22.67 & 25.44 & May.-Ağ. & $0.09-1.70$ & $\begin{array}{l}4361^{-} \\
74861\end{array}$ & $\begin{array}{l}1.02^{-} \\
1.20\end{array}$ & $\begin{array}{l}1.06^{-} \\
1.18\end{array}$ \\
\hline $7 \mathrm{c}$ & $\begin{array}{l}0.41^{-} \\
7.70\end{array}$ & $\begin{array}{l}0.42^{-} \\
14.3\end{array}$ & 22.95 & 24.82 & May.-Ağ. & $0.69-1.79$ & $\begin{array}{l}4102^{-} \\
55985\end{array}$ & $\begin{array}{l}0.92^{-} \\
1.22\end{array}$ & $\begin{array}{l}0.97- \\
1.11\end{array}$ \\
\hline 8 & $\begin{array}{l}0.10^{-} \\
12.0^{-} \\
\end{array}$ & $\begin{array}{l}0.07^{-} \\
10.8 \\
\end{array}$ & 19.35 & 20.77 & $\begin{array}{l}\text { May.- } \\
\text { Tem. }\end{array}$ & $0.21-1.55$ & $\begin{array}{l}1362^{-} \\
15428\end{array}$ & $\begin{array}{l}0.82^{-} \\
1.09 \\
\end{array}$ & $\begin{array}{l}0.87^{-} \\
1.16\end{array}$ \\
\hline
\end{tabular}

*Çatal Boy, 1. Polat (1987); 2. Bozkurt (1998); 3. Örün ve Erdemli (2002); 4. Çökmez (2005); 5. Oymak ve ark., (2008); 6. Düşükcan ve Çalta, (2012); 7. Yüce ve ark., (2014); 8. Bu çalışma

Capoeta trutta Uzunçayır Baraj Gölü’nün dominant türlerinden biridir. Türün baraj gölünde devamlılığını sağlamak ve sürdürülebilir maksimum ürün elde edebilmek için avcılığının düzenlenmesi gerekmektedir. Bu bakımdan, bu çalışmada belirlenen üreme döneminde kaçak avcılığın önlenmesi gerekmektedir. Aynı zamanda, ilk eşeysel olgunluk boyundan küçük balıkları avlayan veya seçici olmayan av araçlarının kullanımına izin verilmemelidir.

\section{TEŞEKKÜR}

$\mathrm{Bu}$ projeyi destekleyen TAGEM (TAGEM/HAYSÜD/2013/A11/P-02/01) ve Elazığ Su Ürünleri Araştırma Enstitüsü Müdürlüğü'ne teşekkür ederiz. Capoeta trutta (Heckel, 1843)'nın büyüme özellikllerine yönelik araştırma makalesi 2014 yılında Yunus Araştırma Bülteni Dergisinnin 2. sayısında yayınlanmıştır. 


\section{KAYNAKLAR}

Alp A, Kara C, Büyükçapar HM, Bülbül O 2005. Age, growth and condition of Capoeta capoeta angorae Hanko 1924 from the Upper Water Systems of the River Ceyhan, Turkey. Turk J Vet Anim Sci, 29: 665-676.

Avşar D 1998. Balıkçılık Biyolojisi ve Populasyon Dinamiği. Baki Kitap ve Yayınevi, No: 20, Adana, 303s.

Bagenal TB, Braum E 1978. Eggs and early life history. In: methods for assessment of fish production in freshwaters. (3rd. ed.), IBP Handbook No: 3, Blackwell Scientific Publications, Oxford, London, Edinburg.

Bingel F 2002. Balık Popülasyonlarının İncelenmesi. Baki Kitabevi, Seyhan-Adana, s.404.

Bozkurt R 1998. Atatürk Baraj Gölü'ndeki Acanthobrama marmid Heckel 1843, Capoeta trutta (Heckel, 1843) ve Carasobarbus luteus (Heckel, 1843)'un biyolojik özellikleri üzerinde araştırmalar, Doktora Tezi, Harran Üniversitesi Fen Bilimleri Enstitüsü, Şanlıurfa, 116s.

Ceyhun SB, Erdoğan O 2008. Kilise Deresi'nde (Hınıs) Yaşayan Capoeta capoeta umbla (Heckel, 1843)'nın populasyon yapısı ve dere suyunun bazı özellikleri. Saltuk Buğrahan Atatürk Üniv. Ziraat Fak. Derg., 39(1): 35-41.

Çalta M, Canpolat Ö 2007. Ağır metal kirlilik kaynaklarının Keban Baraj Gölü'nün su kalitesi, Capoeta trutta (Heckel, 1843)'nın üremesi ve gelişimi üzerindeki etkileri. Firat Üniversitesi Bilimsel Araştırma Projeleri Birimi (FÜBAP), Proje No: 996, (Doktora Tezi Projesi).

Çalta M, Canpolat Ö, Nacar A 2001. Elazığ Keban Baraj Gölü'nde yakalanan Capoeta trutta (Heckel, 1843)'da bazı ağır metal düzeylerinin belirlenmesi. IV. Su Ürünleri Sempozyumu, 800-811.

Çelik EŞ, Bircan R 2004. Çanakkale Boğazı'ndaki siyah iskorpit balığı (Scorpaena porcus Linnaeus, 1758)'nın üreme özellikleri üzerine bir araştırma, F. Ü. Fen ve Mühendislik Bilimleri Dergisi, 16(2): 327-335.

Çoban MZ, Düşükcan M 2009. Üç farklı bölgedeki Capoeta trutta (Heckel, 1843) populasyonunun et veriminin karşılaştırılması. e-Journal of New World Sciences Academy (NWSA), 4(3): 107-114.

Çoban MZ, Gündüz F, Yüksel F, Demirol F, Yıldırım T, Kurtoğlu M 2013. Uzunçayır Baraj Gölü (Tunceli) Balık Faunası. Yunus Araştırma Bülteni, 2: 35-44.

Çökmez T 2005. Keban ve Karakaya Baraj Göllerindeki Capoeta trutta (Heckel, 1843) balık türünün büyüme özelliklerinin karşılaştırılması. Yüksek Lisans Tezi, F.Ü. Fen Bilimleri Enstitüsü.

Duman E 2004. Keban Baraj Gölü'nde yaşayan Capoeta trutta Heckel, 1843’ün üreme biyolojisi. F.Ü. Fen ve Mühendislik Bilimleri Dergisi, 16(1): 145-150.
Düşükcan M, Çalta M 2012. Capoeta trutta (Heckel, 1843)'nın Keban, Karakaya ve Atatürk Baraj Gölleri’ndeki populasyonlarını üreme dönemlerinin karşılaştırılması. Fırat Üniv. Fen Bilimleri Dergisi, 24(2): 57-61.

Fowler J, Cohen 1 1992. Practical Statistics for Field Biology, John Wiley and Sons Inc., New York.

Gül A, Yılmaz M, Solak K 1996. Firat Nehri Tohma Suyu' nda yaşayan Capoeta trutta (Heckel,1843)' nın büyüme özellikleri. Tr.J. Zool., 20: 177-185.

Gündüz F, Çoban MZ, Yüksel F, Demirol F, Kurtoğlu M, Yıldız N 2014. Uzunçayır Baraj Gölü'ndeki (Tunceli) Capoeta trutta (Heckel, 1843)'nın Bazı Populasyon Parametreleri. Yunus Araştırma Bülteni, (2): 3-14.

Kalkan E 2008. Growth and reproduction properties of Capoeta trutta (Heckel,1843) in Karakaya Dam Lake. Turk J Zool, 32: 1-10.

King M 1995. Fisheries Biology, Assesment and Management. Fishing News Books, Oxford, England.

Kurt Kaya G, Erol Mercan R, Yüksel F, Kurtoğlu M, Yıldız N, Gündüz F, Demirol F 2013. Tunceli Uzunçayır Baraj Gölü'nde Yaşayan Karabalık (Capoeta trutta Heckel, 1843) ve Siraz (Capoeta umbla Heckel, 1843) Balıklarının Et Verimlerinin İncelenmesi. Yunus Araştırma Bülteni, 4: 9-14.

Mol S, Özden Ö, Oymak SA 2010. Trace metal contents in fish species from Ataturk Dam Lake (Euphrates,Turkey). Turkish Journal of Fisheries and Aquatic Sciences, 10: 209-213.

Oymak SA, Doğan N, Uysal E 2008. Age, growth and reproduction of the Shabut Barbus grypus (Cyprinidae) in Atatürk Dam Lake (Euphrates River), Turkey. Cybium, 32(2): 145-152.

Örün İ, Erdemli AÜ 2002. A Study on blood parameters of Capoeta trutta (Heckel, 1843). Journal of Biological Sciences, 2 (8): 508-511.

Özekinci U, Beğburs CR, Tenekecioğlu E 2003. Keban Baraj Gölü'nde C. c. umbla (Heckel, 1843) ve Capoeta trutta (Heckel, 1843) (Siraz Balığı) avcılığında kullanılan galsama ağlarının seçiciliklerinin araştırılması, E.Ü. Su Ürünleri Dergisi, 20(3-4), 473-479.

Öztürk S, Saler S, Girgin A, Şen D 1997. Karakaya Baraj Gölü'nde yaşayan Capoeta trutta (Heckel, 1843)'nın yaş tayininde en iyi okunan kemiksi yapıların belirlenmesi, IX $\mathrm{Su}$ Ürünleri Sempozyumu 17-19 Eylül, Eğirdir/Isparta,193.

Polat N 1986. Keban Baraj Gölü'ndeki Bazı balıklarda Yaş Belirleme Yöntemleri ile Uzunluk-Ağırlık İlişkileri. Yüksek Lisans Tezi, Elazı̆̆, Fırat Üniversitesi.

Polat N 1987. Age Determination of Capoeta trutta (Heckel, 1843) in Keba Dam Lake. Doğa Tu. J. of Zoology, 11(3): 155-160.

Şen D, Polat N, Ayvaz Y 1987. Keban Baraj Gölü’nde yaşayan Capoeta truttanın sindirim sistemi 
muhteviyatı. Veteriner Hekimler Odası Dergisi, 2(3): 53-58.

Şevik R 1993. Aşağı Fırat sularında yaşayan Capoeta trutta (Heckel, 1843)'nın büyüme durumu ve üreme özellikleri üzerine araştırmalar. Doğu Anadolu Bölgesi I. Su Ürünleri Sempozyumu, 23-25 Haziran, Erzurum,172-200.

Şevik R, Hartavi Ş, Kılıç ÖS, Yüksel M 1998. Atatürk Baraj Gölü Bozova avlak sahası balık türlerinin bazı ekolojik özellikleri üzerine araştırmalar. Doğu Anadolu Bölgesi III. Su Ürünleri Sempozyumu, 1012 Haziran, Erzurum, 589-596.

URL. http://www.dsi.gov.tr. (Erişim tarihi: 15.01.2017)

Wang J, Liu F, Zhang X, Cao WX, Liu HZ, Gao X 2014. Reproductive biology of Chinese minnow Hemiculterella sauvagei Warpachowski, 1888 in the Chishui River, China. J. Appl. Ichthyol., 30: 314-321.

Yalçın Özdilek Ş, Turan C, Solak K, Akyurt İ 2004. Asi Nehri'nde Yaşayan Barbus luteus (Heckel,1843)'un Büyüme Özellikleri. Türk Sucul Yaşam Dergisi, 3: 164-170.
Yapalak S, Yüksel M 1998. Atatürk Baraj Gölü (Frrat)'nde yaşayan Capoeta trutta (Heckel;1843)'nın büyüme özellikleri üzerine bir araştırma. Doğu Anadolu Bölgesi, III Su Ürünleri Sempozyumu, 10-12 Haziran, Erzurum, 535-348.

Yazıcıoğlu O, Yılmaz M 2011. Hirfanlı Baraj Gölü’nde yaşayan siraz balığı [Capoeta sieboldii (Steindachner,1864)]'nin beslenme rejimi. Karadeniz Fen Bilimleri Dergisi, 1(3): 62-73.

Yllmaz F, Solak K 1999. Dicle Nehrinde yaşayan Capoeta trutta (Heckel;1843)'nin beslenme organizmaları ve bu organizmaların aylara ve yaşlara göre değişimleri. Tr. J. of Zoology, 23(3): 973-978.

Yüce S, Gündüz F, Demirol F, Örnekçi GN, Çelik B, Birici N, Şeker T, Özbey N, Küçükyılmaz M, Alpaslan K, Uslu AA, Tepe R, Güneş S, Özbay Ö, Saler S, Aydın R, Sönmez F, Çoban MZ, Şen D 2014. Keban, Karakaya ve Atatürk Baraj Göllerinde Ekonomik Balıkların Bazı Populasyon Parametrelerinin Araştırılması. Elazığ Su Ürünleri Araştırma Enstitüsü Müdürlüğü, Proje No: Tagem/Haysüd/2009/09/01/02. 